\title{
Human chorionic gonadotropin stimulation gives evidence of differences in testicular steroidogenesis in Klinefelter syndrome, as assessed by liquid chromatography-tandem mass spectrometry
}

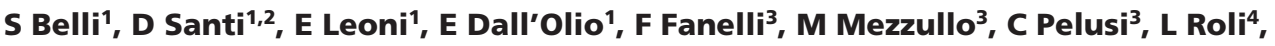 \\ S Tagliavini', T Trenti ${ }^{4}$, A R Granata2 ${ }^{2}$ U Pagotto ${ }^{3}$, R Pasquali ${ }^{3}$, V Rochira ${ }^{1,2}$, \\ C Carani ${ }^{1}$ and $\mathbf{M}$ Simoni ${ }^{1,2,5}$ \\ ${ }^{1}$ Unit of Endocrinology, Department of Biomedical, Metabolic and Neural Sciences, University of \\ Modena and Reggio Emilia, Modena, Italy, ${ }^{2}$ Department of Medicine, Endocrinology, Metabolism and \\ Geriatrics, Azienda USL of Modena, Modena, Italy, ${ }^{3}$ Unit of Endocrinology, Department of Medical and \\ Surgical Sciences, Centre for Applied Biomedical Research, Unit S. Orsola-Malpighi Hospital, Alma Mater \\ University of Bologna, Bologna, Italy, ${ }^{4}$ Department of Laboratory Medicine and Pathological Anatomy, \\ Azienda USL of Modena, Modena, Italy, and ${ }^{5}$ Center for Genomic Research, University of Modena and \\ Reggio Emilia, Modena, Italy
}

Correspondence should be addressed to D Santi

Email santi.daniele@gmail.com

\begin{abstract}
Background: Men with Klinefelter syndrome (KS) show hypergonadotropic hypogonadism, but the pathogenesis of hypotestosteronemia remains unclear. Testicular steroidogenesis in KS men was evaluated over three decades ago after human chorionic gonadotropin (hCG) stimulation, but inconclusive results were obtained. Intriguingly, some recent studies show increased intratesticular testosterone concentrations in men with KS.
\end{abstract}

Objective: To analyze serum steroid profile, as a proxy of testicular steroidogenesis, after hCG stimulation in KS compared with control men.

Design: A prospective, longitudinal, case-control, clinical trial.

Methods: Thirteen KS patients ( $36 \pm 9$ years) not receiving testosterone (TS) replacement therapy and 12 eugonadic controls ( $32 \pm 8$ years) were enrolled. Serum steroids were measured by liquid chromatography-tandem mass spectrometry (LC-MS/MS) at baseline and for five consecutive days after intramuscular injection of $5000 \mathrm{IU}$ hCG. Results: Progesterone (P), 17-hydroxyprogesterone (17OHP), TS, and estradiol (E2) showed a significant increase $(P<0.001)$ after hCG stimulation in both groups. On the contrary, androstenedione (AS) and dehydroepiandrosterone did not increase after hCG stimulation. The 17OHP/P ratio increased in both groups $(P<0.001)$, the TS/AS ratio (17 $\beta$-hydroxysteroid dehydrogenase type $3(17 \beta \mathrm{HSD} 3)$ activity) did not increase after hCG in any group, and the E2/TS ratio (aromatase activity) increased significantly in both groups ( $P=0.009$ in $\mathrm{KS}$ and $P<0.001$ in controls). Luteinizing hormone decreased after hCG in both groups ( $P=0.014$ in KS and $P<0.001$ in controls), whereas follicle-stimulating hormone decreased only in control men $(P<0.001)$.

Conclusion: This study demonstrates for the first time using LC-MS/MS that Leydig cells of KS men are able to respond to hCG stimulation and that the first steps of steroidogenesis are fully functional. However, the TS production in KS men is impaired, possibly related to reduced hydroxysteroid deydrogenase activity due to an unfavorable intratesticular metabolic state.

European Journal of

Endocrinology

(2016) 174, 801-811

C 2016 European Society of Endocrinology Printed in Great Britain
Published by Bioscientifica Ltd. 


\section{Introduction}

Klinefelter syndrome (KS) is the most frequent congenital chromosome aneuploidy with an estimated incidence of 1-2 per 1000 males (1). The karyotype is classically $47, \mathrm{XXY}$, but other variants are found (1). The testes in KS are characterized by extensive fibrosis and hyalinization of the seminiferous tubules and Leydig cells hyperplasia $(1,2,3)$. KS is characterized by hypergonadotropic hypogonadism, and Leydig cells are generally considered dysfunctional and unable to produce adequate levels of testosterone (TS) even if overstimulated by high levels of circulating luteinizing hormone (LH) (2).

TS is the main product of steroidogenesis in the human testis, starting from cholesterol (4). In the first step of steroidogenesis, pregnenolone is $17 \beta$-hydroxylated by P450c17, through two different pathways, depending on the catalytic action of the microsomal enzyme $3 \beta \mathrm{HSD}$ (3- $\beta$-hydroxysteroid dehydrogenase) (5). This enzyme catalyzes both conversion of a hydroxyl group to a keto group and isomerization of the double bond from the $\mathrm{B}$ ring ( $\Delta 5$ steroids) to the $\mathrm{A}$ ring ( $\Delta 4$ steroids) (5) (Supplementary Fig. 1, see section on supplementary data given at the end of this article).

In men, androgens are produced by testes and adrenals in different amounts $(6,7,8)$. Serum TS levels derive mostly from testes, as well as progesterone $(\mathrm{P})$, androstenedione (AS), and 17-hydroxyprogesterone (17OHP) ( $\Delta 4$ pathway). However, the $\Delta 4$ pathway is physiologically almost blocked at the level of 17OHP in Leydig cells (5). A could be considered mainly as a testicular product, because the adrenal zona reticularis shows the lowest $3 \beta \mathrm{HSD} 2$ expression (9), and only small amounts of dehydroepiandrosterone (DHEA) is converted into AS. On the contrary, serum pregnenolone, 17-hydroxypregnenolone, and DHEA (all steroids of the $\Delta 5$ pathway) are mostly expression of adrenal production (5).

Human chorionic gonadotropin (hCG) was used in the past to evaluate testicular steroidogenic reserve (10). The hCG test, however, has never been standardized in KS patients and was variably based on the administration of $5000 \mathrm{IU}$ of hCG as a single intramuscular dose (11); $5000 \mathrm{IU} /$ day for 3 (12), 4 (13), or 5 days (12); $4000 \mathrm{IU} /$ day for 4 (14) or 5 days (15); or 1500 IU/day for 3 days (16). In general, hCG stimulation was followed by an inconsistent rise of serum TS and/or other steroids, lower than in controls, generating the hypothesis of some enzymatic defects of testicular steroidogenesis of KS men $(15,16,17$, $18,19,20)$. It should be noted that some early studies were performed even before radioimmunoassays for TS were in use and were based on competitive binding assays using sex hormone-binding globulin (SHBG) $(14,18)$. In general, most studies hypothesized a specific deficiency in 17-20 lyase activity in KS $(14,15,19)$. The current knowledge is that the 17-20 lyase activity of P450c17 is physiologically almost absent in normal Leydig and granulosa cells (5), and, thus, this hypothesis should be revisited as the mechanism of reduced TS secretion in KS men. A desensitization of Leydig cells to persistent, high, endogenous stimulation by LH was postulated (20). These inconsistent results were unable to clarify the mechanism of reduced TS secretion in KS men, and the issue remained unresolved for over three decades. Recently, a study readdressed the basis of hypogonadism in KS men by measuring serum and intratesticular TS (ITTS) in testis biopsy tissues (21). Intriguingly, this study showed that ITTS is increased in KS men compared with controls, so that the reason for hypotestosteronemia remains even more enigmatic (21).

A liquid chromatography-tandem mass spectrometry (LC-MS/MS) method has been recently validated by us for the simultaneous measurement of nine serum steroids (22). In this study, we applied for the first time this validated technique to analyze basal and hCG-stimulated serum androgens and androgen precursors in patients with KS compared with control subjects. Assuming that some serum steroids, namely, TS, 17OHP, and AS, are a reliable proxy of testicular steroidogenesis $(23,24)$, the aim of the study was a complete reappraisal of hypogonadism in KS by hCG stimulation and using a modern, state-of-the-art approach.

\section{Subjects and methods}

\section{Subjects}

Thirteen KS patients and 12 age-matched, healthy, control subjects were enrolled.

Inclusion criteria for the KS men were as follows: genetic diagnosis of KS by karyotype analysis, elevated serum follicle-stimulating hormone (FSH) levels (>12 IU/L), age between 18 and 45 years, and no current androgen replacement therapy. All KS men included showed karyotype 47 ,XXY.

Inclusion criteria for control group were as follows: normal TS and gonadotropin serum levels, in particular FSH levels $<8 \mathrm{IU} / \mathrm{mL}$, age between 18 and 45 years, and no history of pubertal delay or chronic diseases. 


\section{Study design}

The study design included six visits. During the first visit (visit 0), the subjects underwent physical examination (height, weight, body mass index (BMI), arm span, and upper segment measurement) and testicular ultrasound (US) for the calculation of testicular volume. At $0800 \mathrm{~h}$ of day 0 , all subjects provided a basal blood sample immediately followed by a single intramuscular injection of hCG of $5000 \mathrm{IU}$. Further five visits were performed each of five following consecutive days after the hCG injection. A blood sample was taken at each visit after an overnight fast. Blood samples were then centrifuged at $2955 \boldsymbol{g}$ for $15 \mathrm{~min}$. Sera were transferred into plain polypropylene tubes and stored at $-20^{\circ} \mathrm{C}$ until assayed.

\section{Laboratory analyses}

P, 17OHP, AS, DHEA, and TS were determined by LC-MS/ MS at the laboratory of the Centre for Applied Biomedical Research of the S. Orsola-Malpighi Hospital, Alma Mater Studiorum, University of Bologna, Bologna, Italy. Briefly, samples were purified by solid-phase extraction and injected into a Serie 200HPLC (PerkinElmer) configured in a two-dimensional LC consisting of a first purification on a perfusion column and a second separation on a Luna RP-C8 $100 \times 4.6 \mathrm{~mm}, 5 \mu \mathrm{m}$ (Phenomenex, Torrance, CA, USA) (22). Afterward, analytes underwent atmospheric pressure chemical ionization and multiple reaction monitoring detection by an API4000 QTrap mass spectrometer (AB SCIEX, Toronto, ON, Canada) (22). Intra- and inter-assay coefficient of variation (CV) were $<10$ and $<11 \%$, respectively, and accuracy ranged between 83.7 and $106.2 \%$ for all the analytes (22). The sensitivity in serum matrix was $0.156 \mathrm{nmol} / \mathrm{L}(0.049 \mathrm{ng} / \mathrm{mL})$ for $\mathrm{P}, \quad 0.236 \mathrm{nmol} / \mathrm{L}(0.078 \mathrm{ng} / \mathrm{mL})$ for $17 \mathrm{OHP}, 2.70 \mathrm{nmol} / \mathrm{L}$ $(0.78 \mathrm{ng} / \mathrm{mL})$ for DHEA, $0.136 \mathrm{nmol} / \mathrm{L}(0.039 \mathrm{ng} / \mathrm{mL}$ for A, and $0.066 \mathrm{nmol} / \mathrm{L}(0.019 \mathrm{ng} / \mathrm{mL})$ for TS $(22)$.

SHBG, hCG, LH, FSH, and serum estradiol (E2) were measured by Chemiluminescent Microparticle Immunoassay on the ARCHITECT platform (Abbott Laboratories). The sensitivity was $0.6 \mathrm{pg} / \mathrm{mL}(2.2 \mathrm{pmol} / \mathrm{L})$ with the lowest standard at $1.5 \mathrm{pg} / \mathrm{mL}$, linearity to $150 \mathrm{pg} / \mathrm{mL}$, and an ED50 of $20 \mathrm{pg} / \mathrm{mL}$. The cross-reactivity with estrone and with less potent estrogens was less than 7 and $0.45 \%$, respectively. Free and bioavailable TS levels were calculated using the Vermeulen's algorithm (25). hCG was measured by Chemiluminescent Microparticle Immunoassay on the Beckman platform (DxI800; Beckman Coulter Inc.) with a sensitivity of $0.05 \mathrm{mIU} / \mathrm{L}$.
The ratio between a hormone and its immediate precursor was considered a surrogate of the enzymatic activities above the product. In particular, we calculated the 17OHP/P, TS/AS, and E2/TS ratios.

\section{Testicular ultrasonography}

Testicular volume was calculated by the following formula: length $\times$ width $\times$ height $\times 0.71$. This formula provides a good estimation of testicular volume, and it is recommended in clinical practice (26). US was performed using the Acuson Antares Premium Editions (Siemens, voltage $230 \mathrm{~V} \sim$, frequency 50/60 Hz, Ampere 6-5 A).

\section{Statistical analysis}

Variables were evaluated for normal distribution by the Kolmogorov-Smirnov test. Comparison between basal and stimulated hormonal values was performed by Mann-Whitney $U$ test. Moreover, comparison among different groups was performed by univariate ANOVA when the variables showed normal distribution. Otherwise, the Kruskal-Wallis test was applied for notnormally distributed parameters. Post hoc tests were conducted by Tukey's test or Dunn's test. In order to compare the response to hCG stimulation, areas under the curve (AUCs) were calculated for each hormone using the trapezoid formula and compared using Fisher's exact test.

Statistical analysis was performed using the 'Statistical Package for the Social Sciences' software for Macintosh (version 21.0; SPSS) and SigmaPlot (version 11.00 for Windows; Systat Software, San Jose, CA, USA). For all comparisons, $P$-values of $<0.05$ were considered to be statistically significant.

\section{Ethics statement}

Written informed consent was obtained from all participants, and the study protocol was approved by the Ethics Committee of Modena (File nr. 04/12).

\section{Results}

Testicular volume was significantly higher in the control than in the study group (Table 1). 17OHP, total TS (tTS), free TS (fTS), and bioavailable TS (bTS) were significantly higher at baseline in the control than in the study group, 
Table 1 Baseline characteristics of patients and controls (mean +s.D.).

\begin{tabular}{|c|c|c|c|}
\hline & Control $n=12$ & KS $n=13$ & $P$-value \\
\hline Age (years) & $32.25 \pm 8.84$ & $36.31 \pm 9.57$ & 0.284 \\
\hline BMI $\left(\mathrm{kg} / \mathrm{m}^{2}\right)$ & $28.48 \pm 5.06$ & $25.35 \pm 2.79$ & 0.065 \\
\hline Waist/hip ratio & $0.93 \pm 0.03$ & $0.94 \pm 0.08$ & 0.520 \\
\hline $\begin{array}{l}\text { Testicular volume } \\
(\mathrm{mL})\end{array}$ & $30.30 \pm 10.24$ & $3.34 \pm 0.98$ & $<0.001$ \\
\hline $\begin{array}{l}\text { Upper-to-lower } \\
\text { segment ratio }\end{array}$ & $1.03 \pm 0.05$ & $1.46 \pm 0.94$ & 0.503 \\
\hline $\begin{array}{l}\text { Arm span-to-height } \\
\text { ratio }\end{array}$ & $0.98 \pm 0.17$ & $0.96 \pm 0.16$ & 0.039 \\
\hline hCG (nmoL/L) & $0.30 \pm 0.25$ & $0.60 \pm 0.48$ & 0.770 \\
\hline LH (nmoL/L) & $2.95 \pm 1.11$ & $15.65 \pm 3.00$ & $<0.001$ \\
\hline FSH (nmoL/L) & $3.30 \pm 1.59$ & $26.97 \pm 6.92$ & $<0.001$ \\
\hline $\begin{array}{l}\text { Progesterone } \\
(\mathrm{nmoL} / \mathrm{L})\end{array}$ & $0.29 \pm 0.12$ & $0.28 \pm 0.11$ & 0.999 \\
\hline $170 H P(n m o L / L)$ & $4.53 \pm 2.37$ & $3.03 \pm 0.75$ & 0.040 \\
\hline DHEA (nmoL/L) & $25.481 \pm 16.13$ & $29.44 \pm 24.57$ & 0.810 \\
\hline $\begin{array}{l}\text { Androstenedione } \\
\text { (nmoL/L) }\end{array}$ & $3.49 \pm 1.35$ & $3.91 \pm 2.40$ & 0.936 \\
\hline Testosterone (nmoL/L) & $15.80 \pm 4.58$ & $8.99 \pm 3.54$ & $<0.001$ \\
\hline SHBG (nmoL/L) & $40.83 \pm 22.68$ & $39.36 \pm 15.17$ & 0.999 \\
\hline Estradiol (nmoL/L) & $0.11 \pm 0.03$ & $0.10 \pm 0.03$ & 0.979 \\
\hline
\end{tabular}

whereas LH and FSH were significantly higher in the KS group (Table 1). Curiously, the arm span-to-height ratio was slightly but significantly higher in control than in KS patients.

hCG serum levels were similar at baseline $(P=0.770$, $0.30 \pm 0.25 \mathrm{nmol} / \mathrm{L}$ in the control and $0.60 \pm 0.48 \mathrm{nmol} / \mathrm{L}$ )

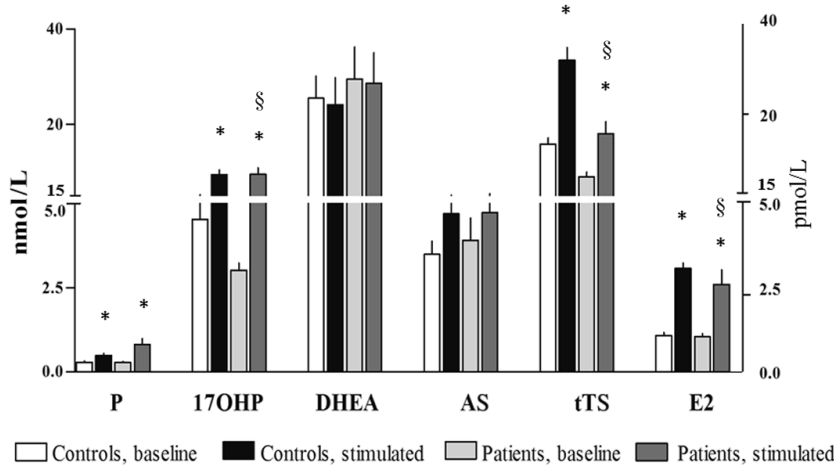

Figure 1

Testicular steroid serum levels ( $\mathrm{nmol} / \mathrm{L})$ at baseline and at peak value reached after hCG stimulation in controls and KS patients. Progesterone (P), 17-hydroxyprogesterone (17OHP), dehydroepiandrosterone (DHEA), androstenedione (AS), total testosterone (tTS), estardiol (E2). *Significantly higher compared with baseline $(P<0.001)$; ${ }^{\S}$ significantly different between groups $(P<0.001)$. and increased significantly and similarly after hCG injection in both groups from basal levels $(P<0.001)$ (Supplementary Fig. 2). Following hCG injection (day 1), serum P, 17OHP, tTS, and E2 increased significantly compared with baseline (day 0) in both groups, whereas DHEA and AS did not, neither in KS nor in control subjects (Fig. 1).

Serum P increased at visit 1 compared with basal in both groups. Moreover, serum P levels at visit 1 were significantly higher compared with visits 3,4 , and 5 both in controls $(P=0.013, P=0.003$, and $P<0.001$, respectively) and in $\mathrm{KS}$ men $(P=0.025, P=0.001$, and $P=0.005$, respectively) (Fig. 2A). The AUC was significantly higher
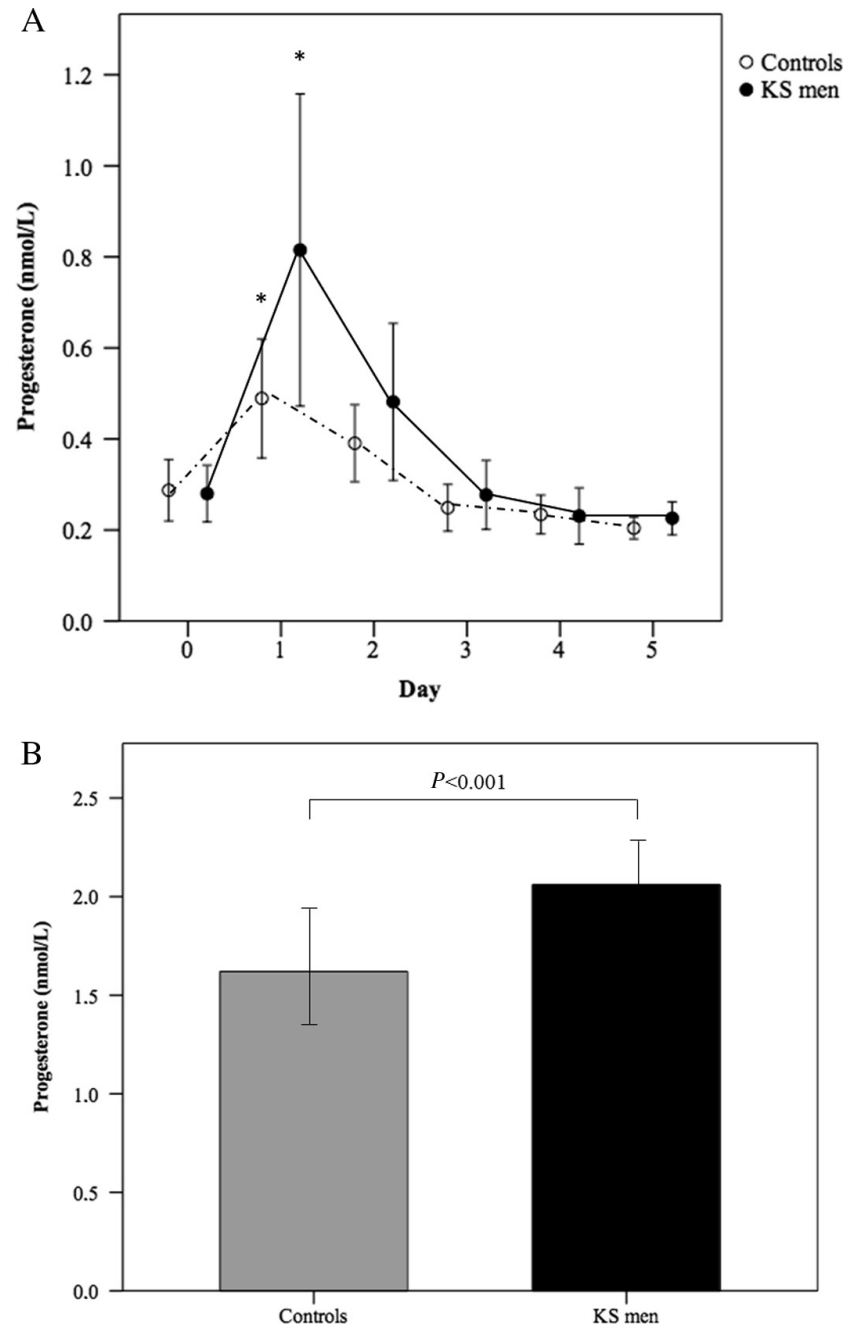

Figure 2

(A) Serum progesterone levels at baseline and after hCG stimulation in controls and KS patients. (B) AUC in controls and KS men. *Significantly higher $P$ levels at visit 1 compared with visits 3,4 , and $5(P=0.013, P=0.003$, and $P<0.001$ for controls and $P=0.025, P=0.001$, and $P=0.005$ for patients). 

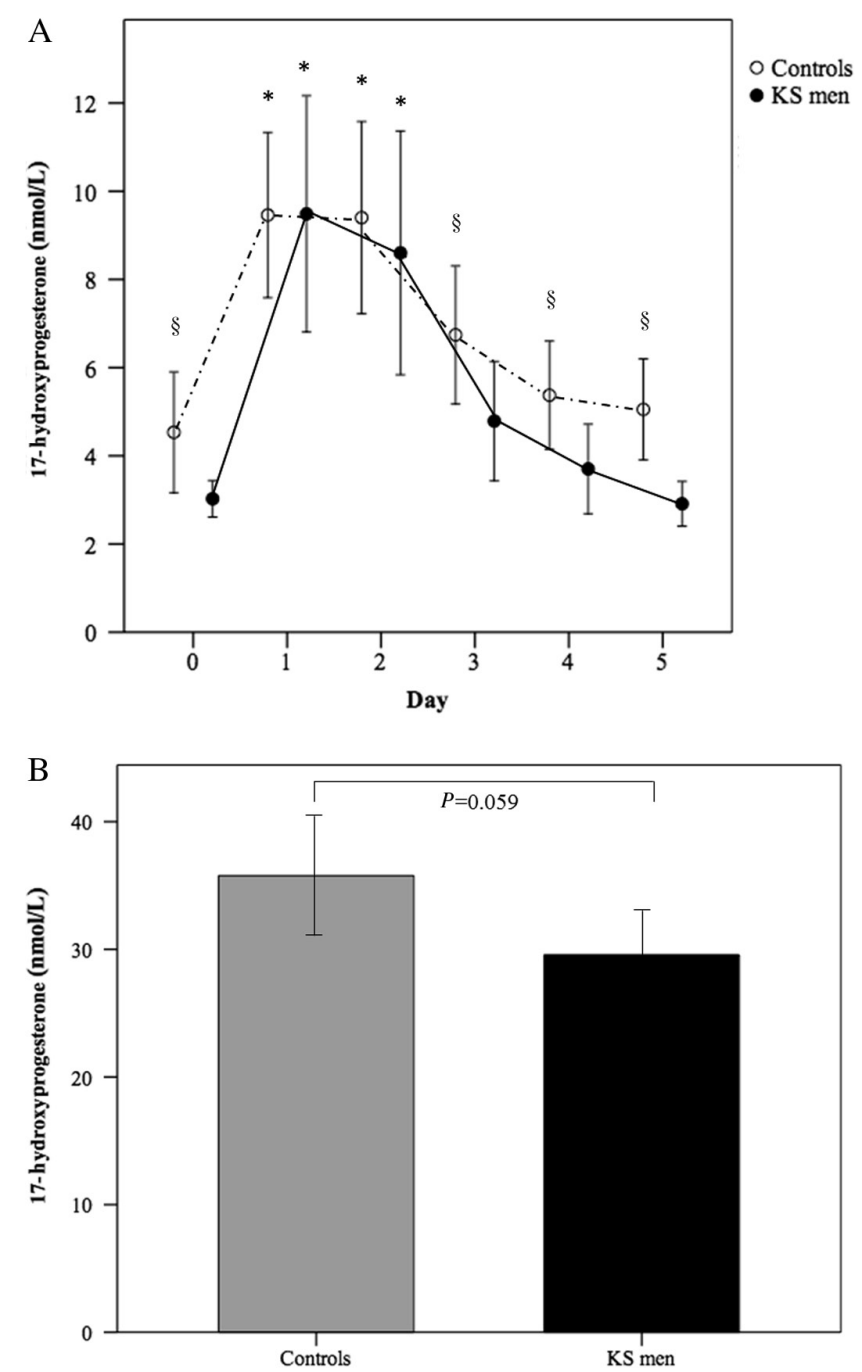

Figure 3

(A) 170HP serum levels at baseline and after hCG stimulation in controls and KS patients. (B) AUC in controls and KS men. §Significant difference between study and control groups ( $P=0.004$ at baseline, $P=0.017$ at visit $3, P=0.017$ at visit 4, and $P=0.007$ at visit 5). *Significant comparison with baseline ( $P=0.002$ in controls and $P=0.001$ in patients at baseline; $P=0.004$ in controls and $P=0.002$ in patients at visit 1 ).

in $\mathrm{KS}$ men compared with controls $(2.06 \mathrm{vs} 1.62 \mathrm{nmol} / \mathrm{L}$, respectively, $P<0.001$ ) (Fig. 2B). Thus, serum $P$ increased more in KS than in control men, reaching top levels at visit 1 and declining thereafter below the basal levels (Fig. 2A and B).

Basal 17OHP was significantly lower in KS men than in controls $(P=0.004)$ and increased similarly after hCG stimulation at visit $1(P=0.002$ in controls, $P=0.001$ in patients) and at visit $2(P=0.004$ in controls, $P=0.002$ in patients) returning to baseline at visit 3 (Fig. 3A). Moreover,
17OHP levels remained significantly higher in the control than in the study group at visits 3,4 , and $5(P=0.017$, $P=0.017$, and $P=0.007$, respectively) (Fig. 3A). The AUC was not significantly different between study and control groups (29.55 vs $35.77 \mathrm{nmol} / \mathrm{L}$, respectively, $P=0.059$ ) (Fig. 3B).

Total TS levels increased significantly at visit 2 in both groups $(P=0.001)$. In the KS group, TS serum levels returned to baseline at visit 3. On the contrary, tTS remained elevated in the control group for the entire study period $(P<0,001, P=0.003$, and $P=0.011$ at visits 3 ,
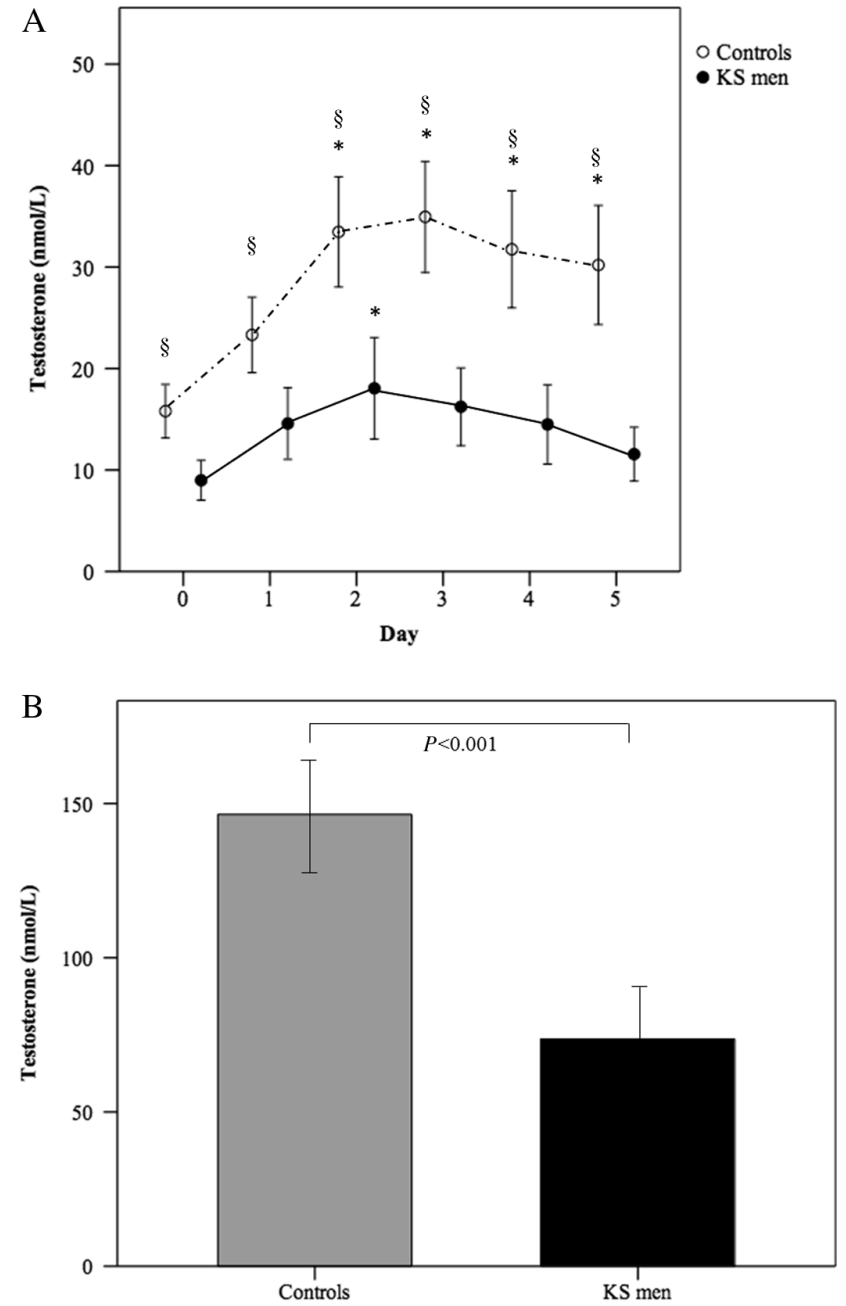

Figure 4

(A) Serum testosterone levels at baseline and after hCG stimulation in controls and KS patients. (B) AUC in controls and KS men. ${ }^{\S}$ Significant comparison between study and control groups $(P<0.001)$. *Significant difference compared with baseline $(P=0.001$ at visit 2 in patients, $P=0.001$ at visit $2, P<0.001$ at visit $3, P=0.003$ at visit 4 , and $P=0.011$ at visit 5 in controls). 

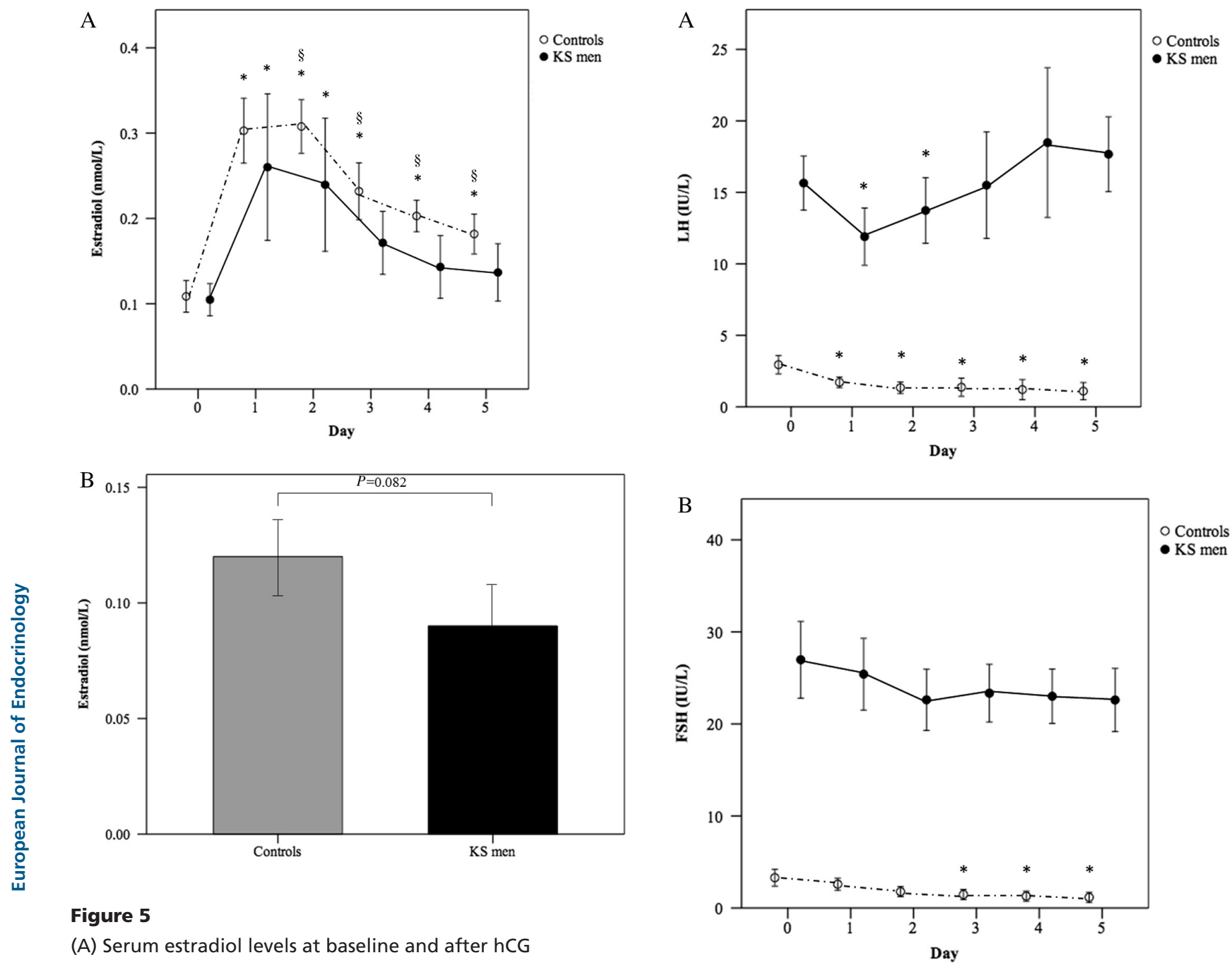

(A) Serum estradiol levels at baseline and after hCG stimulation in controls and KS patients. (B) AUC in controls and KS men. §Significant comparison between study and control groups $(P=0.016, P=0.03, P=0.003$, and $P=0.022$, at visits $2,3,4$, and 5 , respectively). *Significant difference compared with baseline $(P<0.001$ at visit $1, P<0.001$ at visit 2 , and $P=0.003$ at visit 3 in controls; $P=0.001$ at visit 1 and $P=0.020$ at visit 2 in patients).

4, and 5, respectively) (Fig. 4A). The AUC was significantly higher in the control than in the study group (146.47 vs $73.63 \mathrm{nmol} / \mathrm{L}$, respectively, $P<0.001$ ) (Fig. 4B). Moreover, the TS profile was different between groups. In particular, the tTS response to hCG was lasting longer in the control group than in KS men. As SHBG did not change following hCG stimulation, fTS and bTS response mirrored that of tTS in both groups (data not shown).

Serum E2 levels increased significantly after hCG administration in controls at visits 1,2 , and $3(P<0.001$,

\section{Figure 6}

Serum levels of LH (A) and FSH (B) at baseline and after hCG stimulation in controls and KS patients. *Significant difference compared with baseline.

$P<0.001$ and $P=0.003$, respectively) and in $\mathrm{KS}$ men at visits 1 and 2 ( $P=0.001$ and $P=0.020$, respectively). E2 concentrations were significantly higher in controls compared with KS men starting from visit 2 onward $(P=0.016, \quad P=0.03, P=0.003$, and $P=0.022$, at visits $2,3,4$, and 5, respectively) (Fig. 5A). The AUC did not differ between KS and control men $(0.09$ vs $0.12 \mathrm{nmol} / \mathrm{L}$, respectively, $P=0.082$ ) (Fig. $5 \mathrm{~B}$ ).

Serum levels of DHEA, A (Fig. 1), and SHBG (data not shown) did not increase after hCG stimulation in any group, without differences between study and control groups at each time point. 
Table 2 Hormonal ratios at baseline and after hCG stimulation (mean + S.D.).

\begin{tabular}{|c|c|c|c|}
\hline \multirow[b]{2}{*}{ Days } & \multicolumn{3}{|c|}{ 170HP/P } \\
\hline & Control & KS & $P$-value \\
\hline 0 & $15.66 \pm 3.74$ & $11.84 \pm 4.34$ & 0.011 \\
\hline 1 & $20.46 \pm 4.57$ & $14.39 \pm 5.59$ & 0.014 \\
\hline 2 & $24.04 \pm 3.54$ & $19.01 \pm 7.03$ & 0.026 \\
\hline 3 & $26.98 \pm 6.48$ & $17.75 \pm 5.63$ & 0.001 \\
\hline 4 & $23.35 \pm 8.66$ & $16.42 \pm 5.46$ & 0.019 \\
\hline 5 & $24.31 \pm 6.92$ & $13.34 \pm 3.85$ & 0.001 \\
\hline$P$-value & $<0.001$ & $<0.001$ & \\
\hline
\end{tabular}

\begin{tabular}{cccrr}
\hline & \multicolumn{1}{c}{ TS/AS } & \\
\cline { 1 - 1 } Control & & $\mathrm{KS}$ & & $P$-value \\
\cline { 1 - 1 } $7.17 \pm 2.4$ & & $3.06 \pm 2.19$ & & 0.019 \\
$7.03 \pm 2.6$ & & $4.04 \pm 2.04$ & & 0.007 \\
$7.5 \pm 2.23$ & & $4.39 \pm 2.04$ & & 0.004 \\
$7.73 \pm 2.36$ & & $4.19 \pm 1.99$ & & 0.001 \\
$7.61 \pm 2.64$ & & $4.0 \pm 1.98$ & & 0.001 \\
$7.87 \pm 2.21$ & & $3.38 \pm 1.84$ & & $<0.001$ \\
0.116 & & 0.3 & &
\end{tabular}

\begin{tabular}{|c|c|c|}
\hline \multicolumn{3}{|c|}{ E2/TS } \\
\hline Control & KS & $P$-value \\
\hline $0.07 \pm 0.02$ & $0.13 \pm 0.06$ & $<0.001$ \\
\hline $0.14 \pm 0.03$ & $0.18 \pm 0.07$ & 0.77 \\
\hline $0.10 \pm 0.02$ & $0.14 \pm 0.06$ & 0.011 \\
\hline $0.07 \pm 0.02$ & $0.12 \pm 0.05$ & 0.002 \\
\hline $0.07 \pm 0.03$ & $0.11 \pm 0.06$ & 0.019 \\
\hline $0.07 \pm 0.02$ & $0.13 \pm 0.05$ & $<0.001$ \\
\hline$<0.001$ & $<0.009$ & \\
\hline
\end{tabular}

The comparison between patients and controls (columns) and among visits (last row) was considered significant when $P<0.05$.

LH and FSH levels were significantly higher in KS patients than in the control group at baseline (Table 1) and at each time point after hCG stimulation $(P<0.001)$ (Fig. 6). LH rapidly decreased after hCG administration both in control and study groups $(P<0.001$ and $P=0.014$, respectively). Post hoc test showed that serum LH levels were significantly higher at baseline than at visits 2,3 , 4 , and $5(P=0.046, P=0.016, P=0.001$, and $P<0.011$, respectively) in the control group. In the KS group, LH initially decreased until visit 3, increasing immediately thereafter up to levels even higher than basal, with levels at visit 1 significantly lower than at visit $5(P=0.021)$ (Fig. 6A).

FSH significantly and progressively decreased after hCG stimulation only in the control group $(P<0.001)$, with values higher at baseline than at visits 3,4 , and 5 ( $P=0.031, P=0.005$, and $P=0.001$, respectively) (Fig. 6B).

\section{Hormonal ratios}

We assumed the 17OHP/P ratio to represent a parameter mainly of the enzymatic activity of P450c17, also known as $17 \alpha$-hydroxylase. This activity was stimulated by hCG, and a significant increase in this ratio in both groups $(P<0.001)$ was observed (Table 2$)$. At post hoc test, the $17 \mathrm{OHP} / \mathrm{P}$ ratio was lower at baseline than at visits 2 , 3 , and 5 in the control group $(P=0.021, P<0.001$ and $P=0.010$, respectively). In men with $\mathrm{KS}$, the $17 \mathrm{OHP} / \mathrm{P}$ ratio was significantly higher than at baseline only at visit $3(P=0.033)$. Moreover, the $17 \mathrm{OHP} / \mathrm{P}$ ratio was significantly higher in the control than in the study group at each time point (Table 2). These results suggest a stronger stimulatory activity of hCG on P conversion rate in controls than in KS men, in line with significantly higher accumulation of P in KS (Fig. 2B).

The TS/AS was considered as an index mainly of the efficiency of conversion of AS into TS, involving the enzymatic activity of $17 \beta \mathrm{HSD} 3$. Following hCG stimulation, the TS/AS ratio remained stable, both in controls and in KS patients. However, the TS/AS ratio was significantly higher in the control than in the study group at all time points (Table 2). This result suggests a constitutive, higher activity of the final production step of TS in controls versus KS patients with a constant, 'default' conversion of testicular AS to TS independent of gonadotropin stimulation.

TheE2/TS ratio, reflecting aromatase activity, increased significantly after hCG stimulation both in controls and in KS men $(P<0.001$ and $P=0.009$, respectively). In healthy subjects, the post hoc test showed that the E2/TS ratio was higher compared with baseline at visits 1,3 , 4, and $5(P=0.003, P=0.001, P=0.001$ and $P<0.001$, respectively). In KS men, the post hoc test analysis showed that the E2/TS ratio was lower at visit 1 than at visits 3 and 4 ( $P=0.021$ and $P=0.009$, respectively). Furthermore, the E2/TS ratio was significantly higher in KS than in controls at baseline and at visits 2, 3, 4, and 5 (Table 2). These results suggest a relatively higher aromatization rate in KS men than in controls. Furthermore, aromatase is promptly stimulated by hCG, because both the highest $\mathrm{E} 2$ concentration and E2/TS ratio are reached already on day 1 in both groups.

\section{Discussion}

This is the first description of Leydig cell response to exogenous hCG stimulation in KS and in controls using LC-MS/MS for evaluating serum steroids. In this study, we chose to apply one shot injection of $5000 \mathrm{IU}$ of hCG and followed serum steroids daily for 5 days after stimulation. This experimental design explores the response of Leydig cells to hCG stimulation in the short/middle term. The results show that, in the control group, maximal serum TS levels are reached on day 3 after stimulation and slowly decrease thereafter. Serum TS levels on 
day 3 are more than double compared with baseline, confirming recent data in control men, in which the same dose of hCG was applied and TS was measured by radioimmunoassay after extraction and chromatography $72 \mathrm{~h}$ after stimulation (27). Given its long half-life, serum hCG levels were not returned to baseline at the end of the observation period (Supplementary Fig. 2) in the control group. Conversely, in KS men, serum TS levels increased significantly less than in controls, with maximal levels attained on day 2 and returning to levels not statistically significant from baseline already on day 3 in spite of similar serum hCG levels. Therefore, TS production can be further stimulated in KS men, but hCG stimulation is less efficient compared with age-matched, control subjects. These results are barely comparable to those described in the old studies of over three decades ago, in which very different stimulation protocols, observation periods, and assay methods were used $(19,20)$. In accordance with those early studies, the current data confirm and reinforce the concept of a reduced testicular ability to respond to gonadotropin stimulation in KS men.

The mechanism of such reduced TS production in KS men remains, however, challenging. In this study, we show that the response of $\mathrm{P}$ is higher in KS patients and the increase of 17OHP after hCG is maximal and identical to that of control subjects already at day 1 . This suggests that the first steps of the $\Delta 4$ pathway are fully functional in KS Leydig cells, even if the conversion of PS into 17OHP appears significantly more efficient in control men, as indicated by a significantly higher 17OHP/P ratio at each time point. In addition, the $17 \mathrm{OHP} / \mathrm{P}$ ratio increases significantly after hCG stimulation, suggesting a direct control of this gonadotropin on gene expression of the steroidogenic enzyme(s) involved in 17OHP production. The conversion of $\mathrm{P}$ into $17 \mathrm{OHP}$ is the result of P450c17-P450 oxidoreductase (POR) activity, which is known to be stimulated by cAMP. Other enzymatic activities may be involved, for example, 3ßHSD2. Testicular steroidogenesis can be stimulated by LH and hCG, sharing the same LH/choriogonadotropin receptor (LHCGR). However, hCG has higher in vitro activity than LH in terms of cAMP production (28). Moreover, Park and coworkers have recently demonstrated that hCG induces steroidogenic enzyme in vivo in male mice and in vitro in mouse Leydig tumor cells (mLTC-1) (29). In particular, in vitro, after multiple injection of hCG, mRNA levels of steroidogenic enzymes (STAR, 3BHSD, CYP17, and 17ßHSD) decreased markedly in mLTC-1 cells (29). Similarly, in vivo models show an increased production

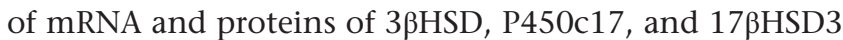
during the first $12 \mathrm{~h}$ after daily hCG treatment (29). This increase is followed by a gradual decrease in further $24 \mathrm{~h}$ (29). Our results seem to confirm this positive effect of hCG stimulation both in controls and in KS men. In addition, our data confirm that 17OHP is a terminal product in Leydig cells, as indicated by the very high values of the 17OHP/P ratios, suggestive for a progressive accumulation (and secretion in blood) of 17OHP due to the very low 17-20 lyase activity of the P450c17 enzyme owing to its low affinity for $17 \mathrm{OHP}(5,30)$.

The peak of TS production is reached at least 1 or 2 days later compared with the 17OHP maximal stimulation, in accordance with the preferential usage of the $\Delta 5$ pathway, which cannot be accurately assessed by measuring serum steroids. In fact, serum pregnenolone, 17OH-pregnenolone, and DHEA are considered to be primarily of adrenal origin, and androstenediol could not be measured by the method applied here. Similarly, the efficiency of $\Delta 5-4$ isomerase (3ßHSD2) activity cannot be extrapolated by calculating the AS/DHEA ratio, given the main adrenal origin of DHEA and testicular origin of AS measured in serum $(23,24)$. In addition, serum A does not increase after hCG, showing that the later steps of TS production do not require direct stimulation of $3 \beta \mathrm{HSD} 2$ and $17 \beta$ HSD3 activity by the gonadotropin. In fact, the TS/ AS ratio does not change following hCG stimulation, as shown by the current data. The TS/AS ratio, however, is significantly higher in controls than in KS patients, possibly identifying at least $17 \beta \mathrm{HSD} 3$ activity as one impaired step of testicular steroidogenesis in this form of primary hypogonadism. $3 \beta \mathrm{HSD} 2$ may be involved as well, but this cannot be proven by the present data.

$3 \beta H S D 2$ and $17 \beta H S D 3$ are HSDs and function by using nicotinamide cofactors NADPH/NADP ${ }^{+}$and NADH/ $\mathrm{NAD}^{+}$. The intracellular concentration of these cofactors exceed that of steroids by many orders of magnitude and is the ultimate driver of the direction and amount of steroidogenic HSD reactions (31). As the nicotinamide cofactors abundance depends on the intracellular redox state, HSD activity may be significantly influenced by the metabolic state of the cell (31). Therefore, local hypoxia and reduced blood flow may be responsible for reduced $17 \beta \mathrm{HSD} 3$ and possibly $3 \beta \mathrm{HSD} 2$ activity in the fibrotic testis of KS patients. A significant reduction of testicular vascularization was previously demonstrated in a mouse model of the human KS (21) and KS patients, which shows significantly reduced artery diameter in several organs (32). We suggest that the decreased TS 
production in the human KS testis may, at least in part, be related to impaired HSD activity as indicated by the significantly reduced TS/AS ratios, owing to reduced tissue oxygenation. However, we cannot exclude a secretion, rather than production, impairment, for instance, due to the inability of ITTS to reach the bloodstream in KS. The hypothesis of dysfunctional Leydig cells in KS has been recently debated by Tuttelmann and coworkers (21), who found significantly increased ITTS concentrations in a mouse model of KS and in human testicular biopsies of $11 \mathrm{KS}$ patients in spite of reduced serum TS levels (21). The authors suggested that an altered vascularization prevents the release of TS into the bloodstream (21). Therefore, a reduced vascular bed in the KS testis may be responsible for both decreased TS production and release into the bloodstream, but this needs to be tested in further studies. All these hypotheses derive from the current knowledge of the enzymatic processes involved in steroidogenesis, which, however, involve different pathways simultaneously. As the serum steroids measured here derive both from the testis and from the adrenal gland, a limitation of this study is that hCG stimulation was performed without suppressing the adrenal gland (e.g., by dexamethasone). However, considering that hCG acts (almost) exclusively on the testis, the results obtained may be assumed informative of testicular steroidogenesis. A more insightful analysis of testicular steroidogenesis in vivo might require repeating the experiment after adrenal suppression.

Finally, serum E2 increased significantly and early (day 1) after hCG stimulation in both groups. This result has to be carefully considered, because E2 is measured using immunoassay and not LC-MS/MS. The quick response of E2 to hCG reflects the rapid stimulation of CYP19 expression by this gonadotropin in the target cell (28). However, lower serum concentrations of E2 in KS than in controls probably depend on the higher TS levels in eugonadal men, because aromatization is more efficient in KS subjects, as suggested by the significantly higher $\mathrm{E} 2 / \mathrm{TS}$ ratios. This is in agreement with evidence of stronger aromatase immunostaining in Leydig cells of KS men (33) and of higher aromatase CYP19 expression in the KS testes (34). Moreover, the high endogenous LH levels could explain the increased aromatase activity in KS. In fact, it is well known that aromatase enzyme (CYP19A1 gene) is an early-response target of $\mathrm{LH}$ both in the human and in mice $(35,36,37)$.

The prompt reduction of serum LH both in KS and in control men after hCG indicates integrity of the negative feedback induced by TS and E2 at the hypothalamic-pituitary level. LH, however, returned to baseline already on day 3 in KS men, reflecting the changes in serum TS levels. Serum FSH levels decreased significantly only in controls starting from day 3 . This different response between controls and KS men could be explained by a different inhibin B production in KS men (38).

In conclusion, we demonstrate here, for the first time using LC-MS/MS, that Leydig cells of KS men are able to respond to hCG stimulation and that the first steps of steroidogenesis are fully functional. TS secretion/ production, however, is impaired, possibly related to reduced HSD activity due to an unfavorable intratesticular metabolic state.

\section{Supplementary data}

This is linked to the online version of the paper at http://dx.doi.org/10.1530/ EJE-15-1224.

\section{Declaration of interest}

The authors declare that there is no conflict of interest that could be perceived as prejudicing the impartiality of the research reported.

\section{Funding}

This research did not receive any specific grant from any funding agency in the public, commercial or not-for-profit sector.

\section{Acknowledgments}

This study was supported by a grant of the Italian Ministry of Education, University and Research (PRIN 2010C8ERKX). DS, MD, is a PhD fellow of the Doctorate School in Clinical and Experimental Medicine of the University of Modena and Reggio Emilia, Italy.

\section{References}

1 Lanfranco F, Kamischke A, Zitzmann M \& Nieschlag E. Klinefelter's syndrome. Lancet 2004364 273-283. (doi:10.1016/S01406736(04)16678-6)

2 Host C, Skakkebaek A, Groth KA \& Bojesen A. The role of hypogonadism in Klinefelter syndrome. Asian Journal of Andrology 201416 185-191. (doi:10.4103/1008-682X.122201)

3 Aksglaede L \& Juul A. Testicular function and fertility in men with Klinefelter syndrome: a review. European Journal of Endocrinology 2013 168 R67-76. (doi:10.1530/EJE-12-0934)

4 Fluck CE \& Pandey AV. Steroidogenesis of the testis - new genes and pathways. Annales d'Endocrinologie 201475 40-47. (doi:10.1016/j. ando.2014.03.002)

5 Miller WL \& Auchus RJ. The molecular biology, biochemistry, and physiology of human steroidogenesis and its disorders. Endocrine Reviews 201132 81-151. (doi:10.1210/er.2010-0013)

6 McKenna TJ, Fearon U, Clarke D \& Cunningham SK. A critical review of the origin and control of adrenal androgens. Baillière's Clinical Obstetrics and Gynaecology 199711 229-248. (doi:10.1016/S09503552(97)80035-1) 
7 Oettel M \& Mukhopadhyay AK. Progesterone: the forgotten hormone in men? Aging Male 20047 236-257. (doi:10.1080/13685530400004199)

8 Rainey WE \& Nakamura Y. Regulation of the adrenal androgen biosynthesis. Journal of Steroid Biochemistry and Molecular Biology 2008 108 281-286. (doi:10.1016/j.jsbmb.2007.09.015)

9 Auchus RJ \& Rainey WE. Adrenarche - physiology, biochemistry and human disease. Clinical Endocrinology 200460 288-296. (doi:10.1046/ j.1365-2265.2003.01858.x)

10 Harrington J \& Palmert MR. Clinical review: distinguishing constitutional delay of growth and puberty from isolated hypogonadotropic hypogonadism: critical appraisal of available diagnostic tests. Journal of Clinical Endocrinology and Metabolism 2012 97 3056-3067.

11 Kolon TF \& Miller OF. Comparison of single versus multiple dose regimens for the human chorionic gonadotropin stimulatory test. Journal of Urology 2001166 1451-1454.

12 Futterweit W, Griboff SI \& Eng Y. Gonadal reserve test in male hypogonadism. Fertility and Sterility 197021 574-580.

13 Fukutani K, Ishida H, Shinohara M, Minowada S, Niijima T \& Isurugi K. Responses of serum testosterone levels to human chorionic gonadotrophin stimulation in patients with Klinefelter's syndrome after long-term androgen replacement therapy. International Journal of Andrology 1983 6-11. (doi:10.1111/j.1365-2605.1983.tb00319.x)

14 Stewart-Bentley M \& Horton R. Leydig cell function in Klinefelter's syndrome. Metabolism 197322 875-884. (doi:10.1016/00260495(73)90060-7)

15 Forti G, Giusti G, Borghi A, Pazzagli M, Fiorelli G, Cabresi E, Mannelli M, Bassi F, Giannotti P, Fusi S et al. Klinefelter's syndrome: a study of its hormonal plasma pattern. Journal of Endocrinological Investigation 19781 149-154. (doi:10.1007/BF03350363)

16 Smals AG, Kloppenborg PW \& Benraad TJ. The effect of short and long term human chorionic gonadotrophin (HCG) administration on plasma testosterone levels in Klinefelter's syndrome. Acta Endocrinologica 197477 753-764.

17 Paulsen CA, Gordon DL, Carpenter RW, Gandy HM \& Drucker WD. Klinefelter's syndrome and its variants: a hormonal and chromosomal study. Recent Progress in Hormone Research 196824 321-363.

18 Ruder HJ, Loriaux DL, Sherins RJ \& Lipsett MB. Leydig cell function in men with disorders of spermatogenesis. Journal of Clinical Endocrinology and Metabolism 197438 244-247. (doi:10.1210/ jcem-38-2-244)

19 Smals AG, Kloppenborg PW, Pieters GF, Losekoot DC \& Benraad TJ. Basal and human chorionic gonadotropin-stimulated 17 alphahydroxyprogesterone and testosterone levels in Klinefelter's syndrome. Journal of Clinical Endocrinology and Metabolism 197847 1144-1147. (doi:10.1210/jcem-47-5-1144)

20 Smals AG, Pieters GF \& Kloppenborg PW. Indirect evidence of chronic Leydig cell desensitization in Klinefelter's syndrome. Acta Endocrinologica $198196552-556$.

21 Tuttelmann F, Damm OS, Luetjens CM, Baldi M, Zitzmann M, Kliesch S, Nieschlag E, Gromoll J, Wistuba J $\&$ Simoni M. Intratesticular testosterone is increased in men with Klinefelter syndrome and may not be released into the bloodstream owing to altered testicular vascularization - a preliminary report. Andrology 20142 275-281. (doi:10.1111/ andr.2014.2.issue-2)

22 Fanelli F, Belluomo I, Di Lallo VD, Cuomo G, De Iasio R, Baccini M, Casadio E, Casetta B, Vicennati V, Gambineri A et al. Serum steroid profiling by isotopic dilution-liquid chromatography-mass spectrometry: comparison with current immunoassays and reference intervals in healthy adults. Steroids 201176 244-253. (doi:10.1016/j. steroids.2010.11.005)

23 Amory JK, Coviello AD, Page ST, Anawalt BD, Matsumoto AM \& Bremner WJ. Serum 17-hydroxyprogesterone strongly correlates with intratesticular testosterone in gonadotropin-suppressed normal men receiving various dosages of human chorionic gonadotropin. Fertility and Sterility 200889 380-386. (doi:10.1016/j. fertnstert.2007.02.059)

24 Roth MY, Page ST, Lin K, Anawalt BD, Matsumoto AM, Marck B, Bremner WJ \& Amory JK. The effect of gonadotropin withdrawal and stimulation with human chorionic gonadotropin on intratesticular androstenedione and DHEA in normal men. Journal of Clinical Endocrinology and Metabolism 201196 $1175-1181$

25 Vermeulen A, Verdonck L \& Kaufman JM. A critical evaluation of simple methods for the estimation of free testosterone in serum. Journal of Clinical Endocrinology and Metabolism 199984 3666-3672.

26 Goede J, Hack WW, Sijstermans K, van der Voort-Doedens LM, Van der Ploeg T, Meij-de Vries A \& Delemarre-van de Waal HA. Normative values for testicular volume measured by ultrasonography in a normal population from infancy to adolescence. Hormone Research in Paediatrics 201176 56-64.

27 Costanzo PR, Suarez SM, Scaglia HE, Zylbersztein C, Litwak LE \& Knoblovits P. Evaluation of the hypothalamic-pituitary-gonadal axis in eugonadal men with type 2 diabetes mellitus. Andrology 20142 117-124. (doi:10.1111/andr.2013.2.issue-1)

28 Casarini L, Lispi M, Longobardi S, Milosa F, La Marca A, Tagliasacchi D, Pignatti E \& Simoni M. LH and hCG action on the same receptor results in quantitatively and qualitatively different intracellular signalling. PLOS ONE 20127 e46682.

29 Park SJ, Kim TS, Park CK, Lee SH, Kim JM, Lee KS, Lee IK, Park JW, Lawson MA \& Lee DS. hCG-induced endoplasmic reticulum stress triggers apoptosis and reduces steroidogenic enzyme expression through activating transcription factor 6 in Leydig cells of the testis. Journal of Molecular Endocrinology 201350 151-166. (doi:10.1530/JME12-0195)

30 Simonov AN, Holien JK, Yeung JC, Nguyen AD, Corbin CJ, Zheng J, Kuznetsov VL, Auchus RJ, Conley AJ, Bond AM et al. Mechanistic scrutiny identifies a kinetic role for cytochrome b5 regulation of human cytochrome P450c17 (CYP17A1, P450 17A1). PLoS ONE 2015 10 e0141252.

31 Agarwal AK \& Auchus RJ. Minireview: cellular redox state regulates hydroxysteroid dehydrogenase activity and intracellular hormone potency. Endocrinology 2005146 2531-2538.

32 Foresta C, Caretta N, Palego P, Ferlin A, Zuccarello D, Lenzi A $\&$ Selice R. Reduced artery diameters in Klinefelter syndrome. International Journal of Andrology 201235 720-725. (doi:10.1111/ ija.2012.35.issue-5)

33 Kotula-Balak M, Bablok L, Fracki S, Jankowska A \& Bilinska B. Immunoexpression of androgen receptors and aromatase in testes of patient with Klinefelter's syndrome. Folia Histochemica et Cytobiologica 200442 215-220.

34 Wosnitzer MS \& Paduch DA. Endocrinological issues and hormonal manipulation in children and men with Klinefelter syndrome. American Journal of Medical Genetics Part C: Seminars in Medical Genetics 2013 163C $16-26$.

35 Lindeberg M, Carlstrom K, Ritvos O \& Hovatta O. Gonadotrophin stimulation of non-luteinized granulosa cells increases steroid production and the expression of enzymes involved in estrogen and progesterone synthesis. Human Reproduction 200722 401-406. (doi:10.1093/humrep/del408)

36 Fan HY, Liu Z, Johnson PF \& Richards JS. CCAAT/enhancerbinding proteins (C/EBP)-alpha and -beta are essential for 


\section{Clinical Study}

ovulation, luteinization, and the expression of key target genes. Molecular Endocrinology 201125 253-268. (doi:10.1210/me. 2010-0318)

37 McAllister JM, Mason JI, Byrd W, Trant JM, Waterman MR \& Simpson ER. Proliferating human granulosa-lutein cells in long term monolayer culture: expression of aromatase, cholesterol side-chain cleavage, and 3 beta-hydroxysteroid dehydrogenase. Journal of
Clinical Endocrinology and Metabolism 199071 26-33. (doi:10.1210/ jcem-71-1-26)

38 Cabrol S, Ross JL, Fennoy I, Bouvattier C, Roger M \& Lahlou N. Assessment of Leydig and Sertoli cell functions in infants with nonmosaic Klinefelter syndrome: insulin-like peptide 3 levels are normal and positively correlated with LH levels. Journal of Clinical Endocrinology and Metabolism 201196 E746-E753.

Received 16 December 2015

Revised version received 30 March 2016

Accepted 30 March 2016 